\author{
D.M. Dovletov ${ }^{1,2}$ \\ ${ }^{1}$ Department of Mathematics, Near East University, Nicosia, TRNC, Mersin 10, Turkey \\ ${ }^{2}$ Institute of Mathematics, Ashgabat, Turkmenistan \\ (E-mail: dovlet.dovletov@gmail.com)
}

\title{
Nonlocal boundary value problem with Poisson's operator on a rectangle and its difference interpretation
}

\begin{abstract}
In the present paper, differential and difference variants of nonlocal boundary value problem (NLBVP) for Poisson's equation in open rectangular domain are studied. The existence, uniqueness and a priori estimate of classical solution are established. The second order of accuracy difference scheme is presented. The applications with weighted integral condition are provided in differential and difference variants.
\end{abstract}

Keywords: Poisson's operator, nonlocal boundary value problem, rectangle, difference scheme.

\section{Introduction}

Firstly, NLBVP for Laplace's equation in a rectangular domain was considered by A.V. Bitsadze and A.A. Samarskii [1]. Later, the $n$-dimensional problem was studied by A. L. Skubachevskii [2].

V. A. Il'in and E. I. Moiseev [3] studied 2-d NLBVP with Poisson's operator on rectangle $\Pi$

$$
\left\{\begin{array}{l}
\Delta u=f(x, y),(x, y) \in \Pi=(0,1) \times(0, \pi), \\
u(x, 0)=u(x, \pi)=u(0, y)=0, u(1, y)=\sum_{k=1}^{m} \alpha_{k} u\left(\xi_{k}, y\right), x \in[0,1], y \in[0, \pi], \xi_{k} \in(0,1)
\end{array}\right.
$$

and proved the existence and uniquness of classical solution when $\sum_{k=1}^{m} \frac{1}{2}\left(\alpha_{k}+\left|\alpha_{k}\right|\right) \leq 1$, established a priori estimate $\|u\|_{W_{2}^{2}(\Pi)} \leq C\|f\|_{L_{2}(\Pi)}$ when $-\infty<\sum_{k=1}^{m} \alpha_{k} \leq 1$ and if all $\alpha_{k}, k=\overline{1, m}$ have the same sign and given this condition offered the second order of accuracy difference scheme on a uniform grid.

In [4], E. A. Volkov demonstrated a simple proof of the existence and uniqueness of classical solution for Laplace's equation with the original Bitsadze-Samarskii nonlocal boundary value condition (NLBVC), proposed a finite-difference method on a square mesh that produces a uniform approximation by the second order of accuracy in the difference metric $C$, applied the method to Poisson's equation $\Delta u=g$ when $g \in C^{2, \lambda}$ for $0<\lambda<1$. In [5], he studied a solvability of the multilevel NLBVP for Poisson's operator on rectangular domain by applying the contraction mapping principle.

In [6], A. Ashyralyev established well-posedness of NLBVP in the open square $\Omega=(0,1) \times(0,1)$ by proving the coercive inequalities for solution of the differential problem

$u_{t t}(t, x)+a(x) u_{x x}(t, x)-\delta u(t, x)=f(t, x)$ in $\Omega, u(0, x)=u(t, 0)=u(t, 1)=0, u(1, x)=u(\lambda, x)$ in $\bar{\Omega}$, when smooth functions $a(x)$ and $f(t, x)$ satisfy the conditions

$$
a(x) \geq 0, f(0, x)=0, f(1, x)=f(\lambda, x), 0 \leq x \leq 1,0 \leq \lambda<1,
$$

where $\delta>0$ is sufficiently large number. In $\Omega$, under the condition $\int_{0}^{1}|\rho(t)| d t<1$, E. Ozturk [7] studied well-posedness of NLBVP for elliptic equation with integral type of NLBVC (in $\bar{\Omega}$ ) by reaching the coercive inequalities for solution of the problem

$$
u_{t t}(t, x)+\left(a(x) u_{x}(t, x)\right)_{x}=f(t, x), u(t, 0)=u(t, 1)=0, u(0, x)=\varphi(x),
$$




$$
u(1, x)=\int_{0}^{1} \rho(t) u(t, x) d t+\psi(x)
$$

and offered the first order of accuracy difference scheme against the term $\sum_{j=1}^{N}\left|\rho\left(t_{j}\right) \tau\right|<1, \quad \tau=1 / N$.

By returning to Laplace's operator on rectangular domain we note, that various numerical methods on multilevel and integral type of NLBVPs were researched in [8-11] and other papers.

In the present paper, we generalize and prove the statements of the preliminary abstract [19] and, additionally, apply our results to NLBVP with integral conditions. We study the problem

$$
\left\{\begin{array}{l}
\Delta u(x, y)=f(x, y),(x, y) \in \Pi, \\
u(x, 0)=u(x, \pi)=u(0, y)=0, u(1, y)=\sum_{r=1}^{n} \alpha_{r} u\left(\zeta_{r}, y\right)-\sum_{s=1}^{m} \beta_{s} u\left(\eta_{s}, y\right)=0, x \in[0,1], y \in[0, \pi],
\end{array}\right.
$$

where $f \in C(\bar{\Pi}), \quad \alpha_{r}>0, \quad \beta_{s}>0, \quad 0<\zeta_{1}<\ldots<\zeta_{n}<1$ and $0<\eta_{1}<\ldots<\eta_{m}<1$, $-\infty<\sum_{r=1}^{n} \alpha_{r}-\sum_{s=1}^{m} \beta_{s} \leq 1 \quad$ when $\quad \zeta_{n}<\eta_{1} ; \quad \sum_{r=1}^{n} \alpha_{r} \leq 1 \quad$ when $\zeta_{n} \geq \eta_{1}$. We prove the existence, uniqueness and a priori estimate $\|u\|_{W_{2}^{2}(\Pi)} \leq C\|f\|_{L_{2}(\Pi)}$ of the classical solution. Particularly, we consider the problem when $n=m$ and $\zeta_{r}<\eta_{r}, r=\overline{1, n}$ and for this special subcase we prove the existence, uniqueness and a priori estimate when $\sum_{r=1}^{n} \frac{\left(\alpha_{r}-\beta_{r}\right)+\left|\alpha_{r}-\beta_{r}\right|}{2} \leq 1$. We offer the finite difference variants on a uniform grid and prove the second order of accuracy in terms of $h=\sqrt{h_{1}^{2}+h_{2}^{2}}$ for $h_{1} \leq c_{0} h_{2}, h_{2} \rightarrow 0$ in respect of each difference metrics $C$ and $W_{2}^{2}$.

As an application, we study NLBVP for Poisson's equation with weighted integral condtion (WIC)

$$
\left\{\begin{array}{l}
\Delta u(x, y)=f(x, y),(x, y) \in \Pi, \\
u(x, 0)=u(x, \pi)=u(0, y)=0, u(1, y)=\int_{0}^{1} \rho(x) u(x, y) d x=0,0 \leq x \leq 1,0 \leq y \leq \pi
\end{array}\right.
$$

respectively the behavior of $\rho(x), \rho(x) \in C^{0}\left[\tau_{0}, \tau_{1}\right]$, i.e., $\left[\tau_{0}, \tau_{1}\right] \subset(0,1), \rho(x) \equiv 0$ in $[0,1] \backslash\left[\tau_{0}, \tau_{1}\right]$. We prove the existence, uniqueness and a priori estimate under the conditions on $\rho(x)$ subject to whether or no the weight function changes the sign, whether or no the sign changing acts from plus to minus or vice verca, whether or no the number of sign changes is an even or odd. Particularly, when $\rho(x)$ does not change the sign and $-\infty<\int_{\tau_{0}}^{\tau_{1}} \rho(x) d x \leq 1$, we prove the existence, uniqueness, a priori estimate and offer the second order of accuracy difference sheme.

\section{Differential problem}

We consider NLBVP in the rectangle $\Pi=(0<x<1) \times(0<y<\pi)$

$$
\left\{\begin{array}{l}
\Delta u(x, y)=f(x, y),(x, y) \in \Pi, \\
u(x, 0)=u(x, \pi)=0,0 \leq x<1, u(0, y)=0, \ell[u](y)=0,0 \leq y \leq \pi,
\end{array}\right.
$$

where

$$
\ell[u](y) \equiv u(1, y)-\sum_{r=1}^{n} \alpha_{r} u\left(\zeta_{r}, y\right)+\sum_{s=1}^{m} \beta_{s} u\left(\eta_{s}, y\right),
$$

$0<\zeta_{1}<\ldots<\zeta_{n}<1, \quad 0<\eta_{1}<\ldots<\eta_{m}<1, \quad \zeta_{r} \neq \eta_{s}, \quad \alpha_{r}>0, \quad \beta_{s}>0, \quad r=\overline{1, n}, \quad s=\overline{1, m}$. We study the classical solution $u(x, y) \in C^{2}(\Pi) \cap C(\bar{\Pi})$ that satisfies the equation and all conditions of (1). Further, on default, the symbol $\boldsymbol{A} \boldsymbol{1}$ denotes the term: $-\infty<\sum_{r=1}^{n} \alpha_{r}-\sum_{s=1}^{m} \beta_{s} \leq 1$ holds when $\zeta_{n}<\eta_{1}$. The symbol $\boldsymbol{A} \mathscr{2}$ denotes: $\sum_{r=1}^{n} \alpha_{r} \leq 1$ holds when $\zeta_{n} \geq \eta_{1}$. The $\boldsymbol{A}$ denotes that $\boldsymbol{A} \boldsymbol{1}$ holds or $\boldsymbol{A} \mathscr{2}$ holds. 
Theorem 1. Let $f(x, y) \in C(\bar{\Pi})$. If $\boldsymbol{A}$ holds, then classical solution of (1) exists and it is an unique.

Proof. Assume that classical solution of (1) exists. To prove the uniqueness it is sufficiently to show that $u(x, y) \equiv 0$ if $f(x, y) \equiv 0$. Put $f(x, y) \equiv 0$ in $\bar{\Pi}$. Then $u(x, y)$ is the solution of Laplace's equation, therefore, for each natural number $k \in N$ the function

$$
X_{k}(x)=\sqrt{2 / \pi} \int_{0}^{\pi} u(x, y) \sin (k y) d y
$$

satisfies the equation $X_{k}^{\prime \prime}(x)-k^{2} X_{k}(x)=0, \quad 0<x<1$. Moreover, since $u(0, y)=\ell[u](y)=0$, then

$$
X_{k}(0)=0, \quad X_{k}(1)=\sum_{r=1}^{n} \alpha_{r} X_{k}\left(\zeta_{r}\right)-\sum_{s=1}^{m} \beta_{s} X_{k}\left(\eta_{s}\right) .
$$

Hence, $X_{k}(x)$ is the solution of the multipoint problem

$$
X_{k}^{\prime \prime}(x)-k^{2} X_{k}(x)=0, \quad 0<x<1, \quad X_{k}(0)=0, \quad \ell\left[X_{k}\right]=0,
$$

where $\ell\left[X_{k}\right]=X_{k}(1)-\sum_{r=1}^{n} \alpha_{r} X_{k}\left(\zeta_{r}\right)+\sum_{s=1}^{m} \beta_{s} X_{k}\left(\eta_{s}\right)$. By virtue of mean value (MV) property [12, p. 1198-1199] (see also $[13,18,20]$ ) we get that solution of $(4)$ satisfies the problem ${ }^{1}[17$, p. 92-93]

$$
X_{k}^{\prime \prime}(x)-k^{2} X_{k}(x)=0,0<x<1, \quad X_{k}(0)=0, X_{k}(1)=\alpha X_{k}\left(\zeta_{[k]}\right)-\beta X_{k}\left(\eta_{[k]}\right),
$$

where $^{2} \quad \alpha=\sum_{r=1}^{n} \alpha_{r}, \beta=\sum_{s=1}^{m} \beta_{s}, \zeta_{[k]} \in\left[\zeta_{1}, \zeta_{n}\right], \eta_{[k]} \in\left[\eta_{1}, \eta_{m}\right]$ and $\zeta_{[k]}<\eta_{[k]}$ when $\zeta_{n}<\eta_{1}$. By virtue of [16, p. 1298-1299] we conclude that (5) has only trivial solution since $\boldsymbol{A}$ holds, i.e., $X_{k}(x) \equiv 0$ in the interval $[0,1]$. Hence, from (3), using the completeness of orthonormal system $\{\sqrt{2 / \pi} \sin (k y), k \in N\}$ on the interval $0 \leq y \leq \pi$, we result $u(x, y) \equiv 0$ in $\bar{\Pi}$. Since the uniqueness is proved, then the existence follows from Fredholm's property [2] inherent (1). Theorem 1 is proved.

Theorem 2. Let $f \in C(\bar{\Pi})$. If $\boldsymbol{A}$ holds, then for classical solution of (1) a priori estimate holds

$$
\|u\|_{W_{2}^{2}(\Pi)} \leq C|| f \|_{L_{2}(\Pi)} .
$$

Proof. To prove (6) it is sufficiently to establish the estimates

$$
\left\|X_{k}\right\|_{L_{2}[0,1]} \leq \frac{C_{1}}{k^{2}}\left\|f_{k}\right\|_{L_{2}[0,1]}, \quad\left\|X_{k}^{\prime}\right\|_{L_{2}[0,1]} \leq \frac{C_{2}}{k}\left\|f_{k}\right\|_{L_{2}[0,1]}, \quad\left\|X_{k}^{\prime \prime}\right\|_{L_{2}[0,1]} \leq C_{3}\left\|f_{k}\right\|_{L_{2}[0,1]}
$$

for $k \in N$, where

$$
f_{k}(x)=\sqrt{2 / \pi} \int_{0}^{\pi} f(x, y) \sin (k y) d y,
$$

so that (7) [3, p. 142-143] results in

$$
\|u\|_{W_{2}^{2}(\Pi)} \leq C_{1}\|f\|_{L_{2}(\Pi)}, \quad\left\|u_{x x}\right\|_{W_{2}^{2}(\Pi)} \leq C_{2}\|f\|_{L_{2}(\Pi)}, \quad\left\|u_{x y}\right\|_{W_{2}^{2}(\Pi)} \leq C_{3}\|f\|_{L_{2}(\Pi)},
$$

\footnotetext{
${ }^{1}$ Further in similar obstacles we will say, for example: the problem (4) is reducible to the problem (5), or the nonlocal condition (4) is reducible to the nonlocal condition (5), or we reduce (4) to (5).

${ }^{2}$ Further in this section the symbols $\alpha$ and $\beta$ denote the sums $\alpha=\sum_{r=1}^{n} \alpha_{r}$ and $\beta=\sum_{s=1}^{m} \beta_{s}$.
} 
and, after all, (9) results in (6). Hence, our target is to prove (7). Thereto, using (3) and (8) for equation $\Delta u(x, y)=f(x, y)$ and conditions $u(0, y)=0, u(1, y)=\sum_{r=1}^{n} \alpha_{r} u\left(\zeta_{r}, y\right)-\sum_{s=1}^{m} \beta_{s} u\left(\eta_{s}, y\right)$, we conclude that $X_{k}(x)$ satisfies the nonhomogeneous multipoint problem (this problem was studied in $[16,17]$ )

$$
X_{k}^{\prime \prime}(x)-k^{2} X_{k}(x)=f_{k}(x), 0<x<1, \quad X_{k}(0)=0, X_{k}(1)=\sum_{r=1}^{n} \alpha_{r} X_{k}\left(\zeta_{r}\right)-\sum_{s=1}^{m} \beta_{s} X_{k}\left(\eta_{s}\right) .
$$

Actually, the estimate

$$
\left|X_{k}(1)\right| \leq C \frac{\sqrt{2}}{k^{3 / 2}}\left\|f_{k}(x)\right\|_{L_{2}[0,1]}
$$

results in the estimates (7). Indeed, put $X_{k}(x)=\bar{X}_{k}(x)+\overline{\bar{X}}_{k}(x)$, where $\bar{X}_{k}(x)$ is the solution of

$$
\bar{X}_{k}^{\prime \prime}(x)-k^{2} \bar{X}_{k}(x)=f_{k}(x), 0<x<1, \bar{X}_{k}(0)=\bar{X}_{k}(1)=0,
$$

and $\overline{\bar{X}}_{k}(x)$ is the soluion of

$$
\overline{\bar{X}}_{k}^{\prime \prime}(x)-k^{2} \overline{\bar{X}}_{k}(x)=0,0<x<1, \overline{\bar{X}}_{k}(0)=0, \overline{\bar{X}}_{k}(1)=X_{k}(1) .
$$

Thereby, it is sufficiently to show that the analog of (7) holds for each of the functions $\bar{X}_{k}(x)$ and $\overline{\bar{X}}_{k}(x)$. Thereto, we use the explicit solution of (13) to get

$$
\begin{gathered}
\left\|\overline{\bar{X}}_{k}\right\|_{L_{2}[0,1]} \leq\left|X_{k}(1)\right|\left(\frac{\int_{0}^{1} \sinh ^{2}(k x) d x}{\sinh ^{2} k}\right)^{1 / 2}, \\
\left\|\overline{\bar{X}}_{k}^{\prime}\right\|_{L_{2}[0,1]} \leq k\left|X_{k}(1)\right|\left(\frac{\int_{0}^{1} \cosh ^{2}(k x) d x}{\sinh ^{2} k}\right)^{1 / 2}, \\
\left\|\overline{\bar{X}}_{k}^{\prime \prime}\right\|_{L_{2}[0,1]} \leq k^{2}\left|X_{k}(1)\right|\left(\frac{\int_{0}^{1} \sinh ^{2}(k x) d x}{\sinh ^{2} k}\right)^{1 / 2},
\end{gathered}
$$

and then, in view of $\frac{\int_{0}^{1} \sinh ^{2}(k x) d x}{\sinh ^{2} k} \leq \frac{1}{k}$ and $\frac{\int_{0}^{1} \cosh ^{2}(k x) d x}{\sinh ^{2} k} \leq \frac{5}{2 k}$, from (14)-(16), we get

$$
\left\|\overline{\bar{X}}_{k}\right\|_{L_{2}[0,1]} \leq \frac{C \sqrt{2}}{k^{2}}\left\|f_{k}\right\|_{L_{2}[0,1]}, \quad\left\|\overline{\bar{X}}_{k}^{\prime}\right\|_{L_{2}[0,1]} \leq \frac{C \sqrt{5}}{k}\left\|f_{k}\right\|_{L_{2}[0,1]}, \quad\left\|\overline{\bar{X}}_{k}^{\prime \prime}\right\|_{L_{2}[0,1]} \leq C \sqrt{2}\left\|f_{k}\right\|_{L_{2}[0,1]}
$$

It means that if (11) holds, then (7) holds for the function $\overline{\bar{X}}_{k}(x)$. Moreover, if (11) holds, then (7) holds for $\bar{X}_{k}(x)$ [3, p. 143-144]. Therefore, to establish (7) for $X_{k}(x)$ it is sufficiently to prove (11).

Let we prove (11). In view of $[17,92-93]$ the multipoint problem (10) is reducible to 3-point problem

$$
X_{k}^{\prime \prime}(x)-k^{2} X_{k}(x)=f_{k}(x), 0<x<1, \quad X_{k}(0)=0, \quad X_{k}(1)=\alpha X_{k}\left(\zeta_{[k]}\right)-\beta X_{k}\left(\eta_{[k]}\right),
$$

where the points $\zeta_{[k]} \in\left[\zeta_{1}, \zeta_{n}\right], \eta_{[k]} \in\left[\eta_{1}, \eta_{m}\right]$, so that $\zeta_{[k]}<\eta_{[k]}$ when $\zeta_{n}<\eta_{1}$. Therefore, it is sufficiently to obtain the estimate (11) for the solution of (18) when the term $\boldsymbol{A}$ holds.

Let $\boldsymbol{A} 1$ holds, i.e., $-\infty<\alpha-\beta \leq 1$ and $\zeta_{n}<\eta_{1}$. Put $\operatorname{sign}\left(X_{k}(1) X_{k}\left(\eta_{[k]}\right) X_{k}\left(\zeta_{[k]}\right)\right) \neq 0$. We consider the alternate subcases: $\operatorname{sign}\left(X_{k}(1) X_{k}\left(\eta_{[k]}\right)\right)=-1$ and $\operatorname{sign}\left(X_{k}(1) X_{k}\left(\eta_{[k]}\right)\right)=1$. Note in advance, if $\operatorname{sign}\left(X_{k}(1) X_{k}\left(\eta_{[k]}\right) X_{k}\left(\zeta_{[k]}\right)\right)=0$, then (11) results from the current proof.

Subcase 1.1:

If $\operatorname{sign}\left(X_{k}(1) X_{k}\left(\eta_{[k]}\right)\right)=-1$, then in view of Bolzano theorem $X_{k}\left(\tau_{k}\right)=0$ for $\tau_{k} \in\left(\eta_{[k]}, 1\right)$. Then by virtue of $[3,143-144]$

$$
\left\|X_{k}\right\|_{L_{2}\left[0, \tau_{k}\right]} \leq \frac{1}{k^{2}}\left\|f_{k}\right\|_{L_{2}\left[0, \tau_{k}\right]}, \quad\left\|X_{k}^{\prime}\right\|_{L_{2}\left[0, \tau_{k}\right]} \leq \frac{1}{k}\left\|f_{k}\right\|_{L_{2}\left[0, \tau_{k}\right]} .
$$


Since $X_{k}(0)=0$, then by virtue of Cauchy-Bunyakovskii inequality

$$
\begin{aligned}
& X_{k}^{2}\left(\zeta_{[k]}\right)=\left|\int_{0}^{\zeta_{[k]}}\left[X_{k}^{2}(x)\right]^{\prime} d x\right|=2\left|\int_{0}^{\zeta_{[k]}} X_{k}(x) X_{k}^{\prime}(x) d x\right| \leq 2\left\|X_{k}\right\|_{L_{2}\left[0, \zeta_{[k]}\right]}\left\|X_{k}^{\prime}\right\|_{L_{2}\left[0, \zeta_{[k]}\right]}, \\
& X_{k}^{2}\left(\eta_{[k]}\right)=\left|\int_{0}^{\eta_{[k]}}\left[X_{k}^{2}(x)\right]^{\prime} d x\right|=2\left|\int_{0}^{\eta_{[k]}} X_{k}(x) X_{k}^{\prime}(x) d x\right| \leq 2\left\|X_{k}\right\|_{L_{2}\left[0, \eta_{[k]}\right]}\left\|X_{k}^{\prime}\right\|_{L_{2}\left[0, \eta_{[k]}\right]} .
\end{aligned}
$$

Using (19) in (20) and (21) we get

$$
\left|X_{k}\left(\zeta_{[k]}\right)\right| \leq \frac{\sqrt{2}}{k^{3 / 2}}\left\|\left.f_{k}\right|_{L_{2}[0,1]}, \quad\left|X_{k}\left(\eta_{[k]}\right)\right| \leq \frac{\sqrt{2}}{k^{3 / 2}}\right\| f_{k} \|_{L_{2}[0,1]} .
$$

Put $c_{1}=\alpha+\beta$. From the 3-point condition (18), in view of (22), we obtain the desired estimate

$$
\left|X_{k}(1)\right| \leq c_{1} \frac{\sqrt{2}}{k^{3 / 2}}\left\|f_{k}\right\|_{L_{2}[0,1]}
$$

Subcase 1.2 :

Let $\operatorname{sign}\left(X_{k}(1) X_{k}\left(\eta_{[k]}\right)\right)=1$. Then $\operatorname{sign}\left(X_{k}(1) X_{k}\left(\zeta_{[k]}\right)\right)=1$ in view of (18). By virtue of MV property [12, p. 1198-1199] we reduce the 3 -point condition (18) to

$$
X_{k}(0)=0, X_{k}\left(\xi_{k}\right)=\nu X_{k}\left(\zeta_{[k]}\right)
$$

for $\xi_{k} \in\left[\eta_{[k]}, 1\right]$ and $\nu=\frac{\alpha}{1+\beta}$. Note, $0<\nu \leq 1$ since $\alpha-\beta \leq 1, \quad \zeta_{[k]}<\xi_{k}$ since $\zeta_{[k]}<\eta_{k}$. By virtue of $\left[12\right.$, p. 1199-1200] we specify an appropriate point $\tau_{k} \in\left[\zeta_{[k]}, \xi_{k}\right]$, so that the solution of (18) satisfies the classical boundary value condition

$$
X_{k}(0)=0, \quad X_{k}^{\prime}\left(\tau_{k}\right)+h_{k} X_{k}\left(\tau_{k}\right)=0
$$

for $h_{k} \geq 0$. Therefore, (19) holds [3, 143-144]. Since $\zeta_{[k]} \leq \tau_{k}$, then (20) holds, and then the first estimate $(22)$ holds. Since $X_{k}(1), X_{k}\left(\eta_{[k]}\right), X_{k}\left(\zeta_{[k]}\right)$ have the same sign, then in view of (18)

$$
\begin{gathered}
(1+\beta) \min \left\{\left|X_{k}(1)\right|,\left|X_{k}\left(\eta_{[k]}\right)\right|\right\} \leq \alpha\left|X_{k}\left(\zeta_{[k]}\right)\right| \leq \alpha \frac{\sqrt{2}}{k^{3 / 2}}\left\|f_{k}\right\|_{L_{2}[0,1]}, \\
\min \left\{\left|X_{k}(1)\right|,\left|X_{k}\left(\eta_{[k]}\right)\right|\right\} \leq \frac{\alpha}{1+\beta} \frac{\sqrt{2}}{k^{3 / 2}}\left\|f_{k}\right\|_{L_{2}[0,1]} .
\end{gathered}
$$

Hence, the estimate (11) follows from (26) or, in view of (22), results from (18), i.e.:

$$
\begin{gathered}
\left|X_{k}(1)\right| \leq c_{2} \frac{\sqrt{2}}{k^{3 / 2}}|| f_{k} \|_{L_{2}[0,1]}, \\
c_{2}=\left\{\begin{array}{l}
\frac{\alpha}{1+\beta}, \text { if }\left|X_{k}(1)\right| \leq\left|X_{k}\left(\eta_{[k]}\right)\right|, \\
\frac{\alpha \beta}{1+\beta}+\alpha, \text { if }\left|X_{k}(1)\right|>\left|X_{k}\left(\eta_{[k]}\right)\right| .
\end{array}\right.
\end{gathered}
$$

Let $\boldsymbol{A} \mathscr{2}$ holds, i.e., $\alpha \leq 1$ and $\zeta_{n} \nless \eta_{1}$. Put $\zeta_{[k]} \neq \eta_{[k]}$, because if this two points coincide, then NLBVC (18) transfoms to

$$
X_{k}(0)=0, X_{k}(1)=(\alpha-\beta) X_{k}\left(\xi_{k}\right) \text { for } \xi_{k}=\zeta_{[k]}=\eta_{[k]} \quad \text { while } \quad-\infty<\alpha-\beta<1,
$$

so that the estimate (11) holds in view of [3]. Moreover, we consider the layout $\zeta_{[k]}>\eta_{[k]}$ only, since for the alternate order when $\zeta_{[k]}<\eta_{[k]}$ (note that $-\infty<\alpha-\beta<1$ since $\alpha \leq 1$ ) 
the estimate (16) is proved already in the above case under the term $\boldsymbol{A} \mathbf{1}$. Additionally, we put $\operatorname{sign}\left(X_{k}(1) X_{k}\left(\eta_{[k]}\right) X_{k}\left(\zeta_{[k]}\right)\right) \neq 0$. Note in advance, if $\operatorname{sign}\left(X_{k}(1) X_{k}\left(\eta_{[k]}\right) X_{k}\left(\zeta_{[k]}\right)\right)=0$, then the estimate (11) results from the current proof. In summary, we have to consider the alternate subcases when $\operatorname{sign}\left(X_{k}(1) X_{k}\left(\zeta_{[k]}\right)\right)=-1$ and $\operatorname{sign}\left(X_{k}(1) X_{k}\left(\zeta_{[k]}\right)\right)=1$ for $\eta_{[k]}<\zeta_{[k]}$.

Subcase 2.1:

If $\operatorname{sign}\left(X_{k}(1) X_{k}\left(\zeta_{[k]}\right)\right)=-1$ and $\eta_{[k]}<\zeta_{[k]}$, then by analogy with the subcase 1.1 we obtain all estimates (19)-(23).

Subcase 2.2 :

Put $\operatorname{sign}\left(X_{k}(1) X_{k}\left(\zeta_{[k]}\right)\right)=1$ and $\eta_{[k]}<\zeta_{[k]}$. Then we have the alternate inequalities: $\left|X_{k}\left(\zeta_{[k]}\right)\right| \geq$ $\geq\left|X_{k}(1)\right|$ and $\left|X_{k}\left(\zeta_{[k]}\right)\right|<\left|X_{k}(1)\right|$.

If $X_{k}\left(\zeta_{[k]}\right)=X_{k}(1)$, then by virtue of Rolle's theorem $X_{k}^{\prime}\left(\tau_{k 1}\right)=0$ for $\tau_{k 1} \in\left[\zeta_{[k]}, 1\right]$.

If $\left|X_{k}\left(\zeta_{[k]}\right)\right|>\left|X_{k}(1)\right|$, then $X_{k}(1)=\nu_{k} X_{k}\left(\zeta_{[k]}\right)$ for an appropriate value $\nu_{k}, 0<\nu_{k}<1$. Hence, by virtue of [12, p. 1199-1200] we specify an appropriate point $\tau_{k 2} \in\left[\zeta_{[k]}, 1\right]$, so that the classical boundary value condition holds for $h_{k}>0: \quad X_{k}(0)=0, \quad X_{k}^{\prime}\left(\tau_{k 2}\right)+h_{k} X_{k}\left(\tau_{k 2}\right)=0$. Thereby, if $\left|X_{k}\left(\zeta_{[k]}\right)\right| \geq\left|X_{k}(1)\right|$, then for some $\tau_{k} \in\left[\zeta_{[k]}, 1\right]$ and $h_{k} \geq 0$

$$
X_{k}(0)=0, \quad X_{k}^{\prime}\left(\tau_{k}\right)+h_{k} X_{k}\left(\tau_{k}\right)=0 .
$$

Since $\eta_{[k]}<\zeta_{[k]}$, then using the method of section 1.1 we succesively obtain the estimates (19)-(23). If $\left|X_{k}\left(\zeta_{[k]}\right)\right|<\left|X_{k}(1)\right|$, then $\operatorname{sign}\left(X_{k}\left(\eta_{[k]}\right) X_{k}(1)\right)=\operatorname{sign}\left(X_{k}\left(\eta_{[k]}\right) X_{k}\left(\zeta_{[k]}\right)\right)=-1$ since $\alpha \leq 1$ and because $\operatorname{sign}\left(X_{k}(1) X_{k}\left(\zeta_{[k]}\right)\right)=1$. By virtue of Bolzano theorem $X_{k}\left(\tau_{k}\right)=0$ for $\tau_{k} \in\left[\eta_{[k]}, \zeta_{[k]}\right]$. Then, by analogy with subcase 1.1 we get (19), (21) and the second estimate in (22). Hence, if $\alpha<1$, then in view of $(18)$

$$
(1-\alpha)\left|X_{k}\left(\zeta_{[k]}\right)\right|<\beta \frac{\sqrt{2}}{k^{3 / 2}}|| f_{k} \|_{L_{2}[0,1]} .
$$

Put $c_{3}=\frac{\alpha \beta}{1-\alpha}+\beta$. Using (18), in view of (22) and (28), we obtain the desired estimate

$$
\left|X_{k}(1)\right| \leq c_{3} \frac{\sqrt{2}}{k^{3 / 2}}\left\|f_{k}\right\|_{L_{2}[0,1]} .
$$

At least, if $\left|X_{k}\left(\zeta_{[k]}\right)\right|<\left|X_{k}(1)\right|$ but $\alpha=1$, then to estimate $X_{k}(1)$ we reduce NLBVP (18) to

$$
L\left[X_{k}(x)\right]=f_{k}(x), 0<x<1, \quad X_{k}(0)=0, X_{k}(1)=X_{k}\left(\zeta_{[k]}\right)-\gamma_{k},
$$

where $L\left[X_{k}(x)\right]=X_{k}^{\prime \prime}(x)-k^{2} X_{k}(x)$ and $\gamma_{k}=\beta X_{k}\left(\eta_{[k]}\right)$. In view of the second estimate in (22)

$$
\left|\gamma_{k}\right|<\beta \frac{\sqrt{2}}{k^{3 / 2}}|| f_{k} \|_{L_{2}[0,1]} .
$$

Put $X_{k}(x)$ is the sum $X_{k}(x)=V_{k}(x)+W_{k}(x)$, so that $V_{k}(x)$ is the solution of

$$
L\left[V_{k}(x)\right]=f_{k}(x), 0<x<1, \quad V_{k}(0)=0, V_{k}(1)-V_{k}\left(\zeta_{[k]}\right)=0,
$$

and $W_{k}(x)$ is the solution of

$$
L\left[W_{k}(x)\right]=0,0<x<1, \quad W_{k}(0)=0, W_{k}(1)-W_{k}\left(\zeta_{[k]}\right)=-\gamma_{k} .
$$

The classical solution of (32) exists and is a unique [12, p. 1198-1200]. By virtue of Rolle theorem $V_{k}^{\prime}\left(\tau_{k}\right)=0$ for $\tau_{k} \in\left(\zeta_{[k]}, 1\right)$. Then similar subcase 1.1 the analogs of (19)-(20) and the first estimate $(22)$ hold for $V_{k}(x)$. Hence, since $V_{k}(1)=V_{k}\left(\zeta_{[k]}\right)$

$$
\left|V_{k}(1)\right| \leq \frac{\sqrt{2}}{k^{3 / 2}}\left\|f_{k}\right\|_{L_{2}[0,1]}
$$


On the other hand, for $\mathcal{C}_{k}=-\gamma_{k}\left(1-\frac{\sinh k \zeta_{[k]}}{\sinh k}\right)^{-1}$ the function $W_{k}(x)=\mathcal{C}_{k} \frac{\sinh k x}{\sinh k}$ is the solution of (33) since $1-\frac{\sinh k \zeta_{[k]}}{\sinh k}>0$ for $\zeta_{[k]}<1$. Then, in view of 2-point condition (33),

$$
\left|W_{k}(1)\right| \leq\left(1-\frac{\sinh k \zeta_{[k]}}{\sinh k}\right)^{-1} \beta \frac{\sqrt{2}}{k^{3 / 2}}\left\|f_{k}\right\|_{L_{2}[0,1]} .
$$

Hence, for $M=\frac{\sinh \zeta_{n}}{\sinh 1}$

$$
\left|W_{k}(1)\right| \leq \frac{1}{1-M} \beta \frac{\sqrt{2}}{k^{3 / 2}}|| f_{k} \|_{L_{2}[0,1]}
$$

Then, in view of (34) and (36), $\left|X_{k}(1)\right| \leq c_{4} \frac{\sqrt{2}}{k^{3 / 2}}\left\|f_{k}(x)\right\|_{L_{2}[0,1]}$ for $c_{4}=1+\beta \frac{1}{1-M}$.

Finally we resume, that for the classical solution of (10) the estimate (11) is proved for the constant $C=\max \left\{c_{1}, c_{2}, c_{3}, c_{4}\right\}$. Theorem 2 is proved.

Theorem 3. Let $f \in C(\bar{\Pi}), m=n$ and $\zeta_{r}<\eta_{r}, r=\overline{1, n}$. If $\sum_{r=1}^{n} \frac{\left(\alpha_{r}-\beta_{r}\right)+\left|\alpha_{r}-\beta_{r}\right|}{2} \leq 1$, then classical solution of NLBVP (1) exists, it is an unique and a priori estimate (6) holds.

Proof. Suppose that classical solution exists. In view of Theorem 2, we rewrite (10) as

$$
L\left[X_{k}(x)\right]=f_{k}(x), 0<x<1, \quad X_{k}(0)=0, \quad \ell\left[X_{k}\right]=0,
$$

where $L\left[X_{k}(x)\right]=X_{k}^{\prime \prime}(x)-k^{2} X_{k}(x)$ and $\ell\left[X_{k}\right] \equiv X_{k}(1)-\sum_{r=1}^{n}\left[\alpha_{r} X_{k}\left(\zeta_{r}\right)-\beta_{r} X_{k}\left(\eta_{r}\right)\right]$. To obtain the estimate (11) we put $X_{k}(x)=V_{k}(x)+W_{k}(x)$, so that $V_{k}(x)$ is the solution of problem

$$
L\left[V_{k}(x)\right]=f_{k}(x), 0<x<1, \quad V_{k}(0)=0, V_{k}(1)=0,
$$

and $W_{k}(x)$ is the solution of problem

$$
L\left[W_{k}(x)\right]=0,0<x<1, \quad W_{k}(0)=0, \quad \ell\left[W_{k}\right]=-\ell\left[V_{k}\right] .
$$

For solution of (38) the analog of (7) holds (see Theorem 2). Hence, since $V_{k}(0)=0$ and $\zeta_{r} \in(0,1)$, $\eta_{r} \in(0,1), r=\overline{1, n}$, then

$$
\left|V_{k}\left(\zeta_{r}\right)\right| \leq\left.\frac{\sqrt{2}}{k^{3 / 2}}|| f_{k}\right|_{L_{2}[0,1]}, \quad\left|V_{k}\left(\eta_{r}\right)\right| \leq \frac{\sqrt{2}}{k^{3 / 2}}|| f_{k} \|_{L_{2}[0,1]} .
$$

Therefore,

$$
\left|\ell\left[V_{k}\right]\right| \leq\left(\sum_{r=1}^{n}\left(\alpha_{r}+\beta_{r}\right)\right) \frac{\sqrt{2}}{k^{3 / 2}}\left\|f_{k}\right\|_{L_{2}[0,1]} .
$$

The problem (39) has the solution $W_{k}(x)=\mathcal{W}_{k} \frac{\sinh k x}{\sinh k}, \quad \mathcal{W}_{k}=\frac{-\ell\left[V_{k}\right]}{1-(\sinh k)^{-1} \sum_{r=1}^{n}\left[\alpha_{r} \sinh k \zeta_{r}-\beta_{r} \sinh k \eta_{r}\right]}$, where the denominator of $\mathcal{W}_{k}$ is nozero when $\frac{1}{2} \sum_{r=1}^{n}\left[\left(\alpha_{r}-\beta_{r}\right)+\left|\alpha_{r}-\beta_{r}\right|\right]<1$. In view of (40),

$$
\left|W_{k}(1)\right| \leq \frac{\sqrt{2} \sum_{r=1}^{n}\left(\alpha_{r}+\beta_{r}\right)}{k^{3 / 2}\left[1-\frac{1}{2} \sum_{r=1}^{n}\left(\alpha_{r}-\beta_{r}+\left|\alpha_{r}-\beta_{r}\right|\right)\right]}\left\|f_{k}\right\|_{L_{2}[0,1]} .
$$

Hence, (11) holds since $V_{k}(1)=0$, i.e., $\left|X_{k}(1)\right| \leq C \frac{\sqrt{2}}{k^{3 / 2}}\left\|f_{k}\right\|_{L_{2}[0,1]}$. 
At least, put $\frac{1}{2} \sum_{r=1}^{n}\left[\left(\alpha_{r}-\beta_{r}\right)+\left|\alpha_{r}-\beta_{r}\right|\right]=1$, then similar (35), but in view of (40), we get

$$
\left|W_{k}(1)\right| \leq\left(1-\frac{\sinh \zeta_{p}}{\sinh 1}\right)^{-1}\left[\sum_{r=1}^{n}\left(\alpha_{r}+\beta_{r}\right)\right] \frac{\sqrt{2}}{k^{3 / 2}}\left\|f_{k}\right\|_{L_{2}[0,1]},
$$

where $p, 1 \leq p \leq n$ is a natural number, so that

$$
\frac{\left(\alpha_{p}-\beta_{p}\right)+\left|\alpha_{p}-\beta_{p}\right|}{2}>0, \text { but } \frac{\left(\alpha_{p+i}-\beta_{p+i}\right)+\left|\alpha_{p+i}-\beta_{p+i}\right|}{2}=0 \text { for all } i, p<i \leq n,
$$

and $p=n$ if $i$ does not exists. Hence, (11) holds for $\frac{1}{2} \sum_{r=1}^{n}\left[\left(\alpha_{r}-\beta_{r}\right)+\left|\alpha_{r}-\beta_{r}\right|\right]=1$ since $V_{k}(1)=0$. In summary, for the solution of (37) the estimate (11) holds when $\frac{1}{2} \sum_{r=1}^{n}\left[\left(\alpha_{r}-\beta_{r}\right)+\left|\alpha_{r}-\beta_{r}\right|\right] \leq 1$. Hence, in view of Theorem 2, a priori estimate (6) holds for NLIVP (1), thereto the solution of (1) is a unique and, therefore, in view of Theorem 1 the solution exists. Theorem 3 is proved.

\section{Difference variant}

We consider the difference variant of NLBVP (1)

$$
\left\{\begin{array}{l}
\Lambda Y=Y_{\bar{x} x}+Y_{\bar{y} y}=f\left(x_{i}, y_{j}\right), \quad\left(x_{i}, y_{j}\right) \in \Pi, \\
\left.Y\right|_{y=0}=\left.Y\right|_{y=\pi}=0, x_{i} \in[0,1),\left.\quad Y\right|_{x=0}=0, y_{j} \in[0, \pi] \\
\mathcal{L} Y=\sum_{r=1}^{n} \alpha_{r}\left\{Y_{i_{\zeta r}, j} \frac{\left[\left(i_{\zeta r}+1\right) h_{1}-\zeta_{r}\right]}{h_{1}}+Y_{i_{\zeta_{r}}+1, j} \frac{\left[\zeta_{r}-i_{\zeta_{r}} h_{1}\right]}{h_{1}}\right\}- \\
\quad-\sum_{s=1}^{m} \beta_{s}\left\{Y_{i_{\eta_{s}}, j} \frac{\left[\left(i_{\eta_{s}}+1\right) h_{1}-\eta_{s}\right]}{h_{1}}+Y_{i_{\eta_{s}}+1, j} \frac{\left[\eta_{s}-i_{\eta_{s}} h_{1}\right]}{h_{1}}\right\}-Y_{N_{1}, j}=0, j=\overline{1, N_{2}-1}
\end{array}\right.
$$

where $i_{\zeta_{r}} h_{1} \leq \zeta_{r}<\left(i_{\zeta_{r}}+1\right) h_{1}, \quad r=\overline{1, n}, \quad i_{\eta_{s}} h_{1} \leq \eta_{s}<\left(i_{\eta_{s}}+1\right) h_{1}, \quad s=\overline{1, m} \quad$ for $\quad h_{1}=1 / N_{1}$, $h_{1}<\frac{1}{2} \min \left\{\zeta_{r+1}-\zeta_{r}, r=\overline{0, n}, \eta_{s+1}-\eta_{s}, s=\overline{0, m},\left|\zeta_{r}-\eta_{s}\right|, r=\overline{1, n}, s=\overline{1, m}\right\}, \quad \zeta_{0}=\eta_{0}=0$, $\zeta_{n+1}=\eta_{m+1}=1, \quad h_{1} \leq c_{0} h_{2}, \quad h_{2}=\pi / N_{2}$.

Theorem 4. Let the term $\boldsymbol{A}$ holds and $u \in C^{(4)}(\bar{\Pi})$ is the solution of NLBVP (1). Then solution of the difference problem (41) approximates $u(x, y)$ by the second order of accuracy in terms of $h=\sqrt{h_{1}^{2}+h_{2}^{2}}$ when $h_{2} \rightarrow 0$ in respect of difference metrics $C, W_{2}^{2}$.

Proof. We denote $z=Y-u$ and obtain the difference problem

$$
\Lambda z=f-\Lambda u=F, \quad\left(i h_{1}, j h_{2}\right) \in \Pi,\left.\quad z\right|_{x=0}=\left.z\right|_{y=0}=\left.z\right|_{y=\pi}=0, \quad \mathcal{L} z=-\mathcal{L} u .
$$

For this problem $F=O\left(h^{2}\right), \mathcal{L} u=O\left(h^{2}\right)$ [14, p. 81, 229]. Put $z=\tilde{z}+\hat{z}$, where $\tilde{z}$ is the solution of

$$
\Lambda \tilde{z}=0, \quad\left(i h_{1}, j h_{2}\right) \in \Pi,\left.\quad \tilde{z}\right|_{x=0}=\left.\tilde{z}\right|_{y=0}=\left.\tilde{z}\right|_{y=\pi}=0, \quad \mathcal{L} \tilde{z}=-\mathcal{L} u,
$$

and $\hat{z}$ is the solution of

$$
\Lambda \hat{z}=F,\left(i h_{1}, j h_{2}\right) \in \Pi,\left.\quad \hat{z}\right|_{x=0}=\left.\hat{z}\right|_{y=0}=\left.\hat{z}\right|_{y=\pi}=0, \quad \mathcal{L} \hat{z}=0
$$

To estimate $\tilde{z}$ we use $[14$, p. 113$]$ the orthogonal system of mesh functions $\{\sin (k y)\}_{k=1}^{k=N_{2}-1}$, so that

$$
\tilde{z}=\sum_{k=1}^{N_{2}-1} \tilde{z}_{k} \sin (k y), \quad y=j h_{2}, \overline{j=0, N_{2}}
$$


thereto $\tilde{z}_{k}, \quad k=\overline{1, N_{2}-1}$ is the solution of difference problem

$$
\Lambda_{1} \tilde{z}_{k}-\lambda_{k} \tilde{z}_{k}=0,\left.\quad \tilde{z}_{k}\right|_{x=0}=0, \quad \mathcal{L} \tilde{z}_{k}=-Q_{k}
$$

where $\Lambda_{1} \tilde{z}=\tilde{z}_{\bar{x} x}, \quad \lambda_{k}=4 h_{2}^{-2} \sin ^{2}\left(k h_{2}\right), \quad Q_{k}=(\mathcal{L} u)_{k}$ so that, in view of [3, p. 142-143],

$$
\tilde{z}_{k_{i}}=A_{k} \sinh \left(i \ln q_{k}\right), \quad A_{k}=-Q_{k} / \mathcal{L}\left[\sinh \left(i \ln q_{k}\right)\right], \quad i=\overline{0, N_{1}}, \quad q_{k}=1+\lambda_{k} h_{1}^{2} / 2+\sqrt{\lambda_{k} h_{1}^{2}+\lambda_{k}^{2} h_{1}^{4} / 4} .
$$

By acting $\mathcal{L}$ in the denominator of the fraction $A_{k}$, we get

$$
-\mathcal{L}\left[\sinh \left(i \ln q_{k}\right)\right] \geq \sinh \left(N_{1} \ln q_{k}\right)-\sum_{r=1}^{n} \alpha_{r} \sinh \left(\left(i_{\zeta_{n}}+1\right) \ln q_{k}\right)+\sum_{s=1}^{m} \beta_{s} \sinh \left(i_{\eta_{1}} \ln q_{k}\right) .
$$

Hence,

$$
-\mathcal{L}\left[\sinh \left(i \ln q_{k}\right)\right] \geq \sinh \left(N_{1} \ln q_{k}\right)-S \sinh \left(\left(i_{\zeta_{n}}+1\right) \ln q_{k}\right)
$$

for

$$
S=\left\{\begin{array}{l}
\sum_{r=1}^{n} \alpha_{r}-\sum_{s=1}^{m} \beta_{s}, \text { if } \zeta_{n}<\eta_{1} \\
\sum_{r=1}^{n} \alpha_{r}, \quad \text { if } \quad \zeta_{n}>\eta_{1} .
\end{array}\right.
$$

Then

$$
-\mathcal{L}\left[\sinh \left(i \ln q_{k}\right)\right] \geq C \sinh \left(N_{1} \ln q_{k}\right)
$$

for $C>0$,

$$
C=\left\{\begin{array}{l}
1, \quad \text { if } \quad-\infty<\sum_{r=1}^{n} \alpha_{r}-\sum_{s=1}^{m} \beta_{s} \leq 0, \quad \zeta_{n}<\eta_{1} ; \\
1-\left(\sum_{r=1}^{n} \alpha_{r}-\sum_{s=1}^{m} \beta_{s}\right), \quad \text { if } 0<\sum_{r=1}^{n} \alpha_{r}-\sum_{s=1}^{m} \beta_{s}<1, \quad \zeta_{n}<\eta_{1} \\
1-\sum_{r=1}^{n} \alpha_{r}, \quad \text { if } \alpha_{r}<1, \quad \zeta_{n}>\eta_{1} .
\end{array}\right.
$$

Let we show that when $S=1$ in (47), then the inequality (48) holds for $C=1-\frac{1}{(1+4 / \pi)^{\delta}}$ subject to an appropriate $\delta, 0<\delta \leq 1$. Indeed, in view of (47)

$$
-\mathcal{L}\left[\sinh \left(i \ln q_{k}\right)\right] \geq \sinh \left(N_{1} \ln q_{k}\right)\left[1-\frac{\sinh \left(\left(i_{\zeta_{n}}+1\right) \ln q_{k}\right)}{\sinh \left(N_{1} \ln q_{k}\right)}\right] \geq 0
$$

Hence,

$$
-\mathcal{L}\left[\sinh \left(i \ln q_{k}\right)\right] \geq \sinh \left(N_{1} \ln q_{k}\right)\left[1-\frac{q_{k}^{i_{\zeta_{n}}+1}-q_{k}^{-\left(i_{\zeta_{n}}+1\right)}}{q_{k}^{N_{1}}-q_{k}^{-N_{1}}}\right]
$$

Since $q_{k} \geq 1$, then

$$
\frac{q_{k}^{i_{\zeta_{n}}+1}-q_{k}^{-\left(i_{\zeta_{n}}+1\right)}}{q_{k}^{N_{1}}-q_{k}^{-N_{1}}} \leq \frac{q_{k}^{i_{\zeta_{n}}+1}\left[1-q_{k}^{-2\left(i_{\zeta n}+1\right)}\right]}{q_{k}^{N_{1}}\left[1-q_{k}^{-2 N_{1}}\right]} \leq \frac{q_{k}^{i_{\zeta_{n}}+1}}{q_{k}^{N_{1}}} .
$$

Since $h_{1}<\theta$ for $\theta=\frac{1}{2} \min \left\{\zeta_{r+1}-\zeta_{r}, r=\overline{0, n}, \eta_{s+1}-\eta_{s}, s=\overline{0, m},\left|\zeta_{r}-\eta_{s}\right|, r=\overline{1, n}, s=\overline{1, m}\right\}$, then for specified $\delta=1-\zeta_{n}-\theta$ the inequality $\zeta_{n}+h_{1} \leq 1-\delta$ holds. Hence, $i_{\zeta_{n}}+1 \leq h_{1}^{-1}(1-\delta)$. Then from (60) it follows that

$$
\frac{q_{k}^{i_{\zeta_{n}}+1}-q_{k}^{-\left(i_{\zeta n}+1\right)}}{q_{k}^{N_{1}}-q_{k}^{-N_{1}}} \leq \frac{q_{k}^{N_{1}(1-\delta)}}{q_{k}^{N_{1}}} \leq \frac{1}{q_{k}^{N_{1} \delta}}
$$


Hence, in view of (49),

$$
-\mathcal{L}\left[\sinh \left(i \ln q_{k}\right)\right] \geq\left(1-\frac{1}{q_{k}^{N_{1} \delta}}\right) \sinh \left(N_{1} \ln q_{k}\right) .
$$

Since $q_{k}^{N_{1}} \geq\left(1+\sqrt{\lambda_{k}} h_{1}\right)^{N_{1}} \geq\left(1+\sqrt{\lambda_{1}} h_{1}\right)^{N_{1}} \geq\left(1+\sqrt{\lambda_{1}}\right) \geq 1+\frac{4}{\pi}$, then from (51) we obtain

$$
-\mathcal{L}\left[\sinh \left(i \ln q_{k}\right)\right] \geq\left[1-\frac{1}{(1+4 / \pi)^{\delta}}\right] \sinh \left(N_{1} \ln q_{k}\right) .
$$

In summary, if the term $\boldsymbol{A}$ holds, then

$$
-\mathcal{L}\left[\sinh \left(i \ln q_{k}\right)\right] \geq C \sinh \left(N_{1} \ln q_{k}\right)>0 .
$$

Finally, in view of (53), by virtue of [3, 150-151], we obtain the estimates

$$
\max _{i, j}\left|\tilde{z}_{i j}\right|=O\left(h^{2}\right), \quad\|\tilde{z}\|_{W_{2}^{2}}=O\left(h^{2}\right), \max _{i, j}\left|\hat{z}_{i j}\right|=O\left(h^{2}\right),\|\hat{z}\|_{W_{2}^{2}}=O\left(h^{2}\right) .
$$

Therefore, $\max _{i, j}\left|z_{i j}\right|=O\left(h^{2}\right), \quad\|z\|_{W_{2}^{2}}=O\left(h^{2}\right)$. Theorem 4 is proved.

Corollary 1. Let $n=m, \quad \zeta_{r}<\eta_{r}, \quad r=\overline{1, n}$. Let $u \in C^{(4)}(\bar{\Pi})$ is the solution of NLBVP (1). If $\sum_{r=1}^{n} \frac{\left(\alpha_{r}-\beta_{r}\right)+\left|\alpha_{r}-\beta_{r}\right|}{2} \leq 1$, then difference solution of (41) approximates $u(x, y)$ by the second order of accuracy in terms of $h=\sqrt{h_{1}^{2}+h_{2}^{2}}$ when $h_{2} \rightarrow 0$ in respect of difference metrics $C, W_{2}^{2}$.

Proof. By virtue of (42)-(46) we get the inequality for the denominator of the fraction $A_{k}$ :

$$
-\mathcal{L}\left[\sinh \left(i \ln q_{k}\right)\right] \geq \sinh \left(N_{1} \ln q_{k}\right)-\sum_{r=1}^{n} \alpha_{r} \sinh \left(\left(i_{\zeta_{r}}+1\right) \ln q_{k}\right)+\sum_{r=1}^{n} \beta_{r} \sinh \left(i_{\eta_{r}} \ln q_{k}\right) .
$$

Since $i_{\zeta_{r}}+1<i_{\eta_{r}}, r=\overline{1, n}$, then

$$
-\mathcal{L}\left[\sinh \left(i \ln q_{k}\right)\right] \geq \sinh \left(N_{1} \ln q_{k}\right)-\sum_{r=1}^{n}\left(\alpha_{r}-\beta_{r}\right) \sinh \left(\left(i_{\zeta_{r}}+1\right) \ln q_{k}\right) .
$$

Hence,

$$
-\mathcal{L}\left[\sinh \left(i \ln q_{k}\right)\right] \geq\left[1-\sum_{r=1}^{n}\left(\alpha_{r}-\beta_{r}\right)\left(\frac{q_{k}^{i_{\zeta_{r}}+1}-q_{k}^{-\left(i_{\zeta r}+1\right)}}{q_{k}^{N_{1}}-q_{k}^{-N_{1}}}\right)\right] \sinh \left(N_{1} \ln q_{k}\right)
$$

Then

$$
-\mathcal{L}\left[\sinh \left(i \ln q_{k}\right)\right] \geq\left[1-\sum_{r=1}^{n}\left(\frac{\left(\alpha_{r}-\beta_{r}\right)+\left|\alpha_{r}-\beta_{r}\right|}{2}\right)\left(\frac{q_{k}^{i_{\zeta r}+1}-q_{k}^{-\left(i_{\zeta_{r}}+1\right)}}{q_{k}^{N_{1}}-q_{k}^{-N_{1}}}\right)\right] \sinh \left(N_{1} \ln q_{k}\right) .
$$

Put $p$ is a natural number, $1 \leq p \leq n$, so that

$$
\frac{\left(\alpha_{p}-\beta_{p}\right)+\left|\alpha_{p}-\beta_{p}\right|}{2}>0, \text { but } \frac{\left(\alpha_{p+i}-\beta_{p+i}\right)+\left|\alpha_{p+i}-\beta_{p+i}\right|}{2}=0 \text { for all } i, p<i \leq n
$$

(if such $p$ does not exists, or if such $i$ does not exists, then put $p=n$ ). Hence, in view of (54),

$$
-\mathcal{L}\left[\sinh \left(i \ln q_{k}\right)\right] \geq\left[1-S \frac{q_{k}^{i_{\zeta p}+1}-q_{k}^{-\left(i_{\zeta p}+1\right)}}{q_{k}^{N_{1}}-q_{k}^{-N_{1}}}\right] \sinh \left(N_{1} \ln q_{k}\right)
$$


for $S=\sum_{r=1}^{n} \frac{\left(\alpha_{r}-\beta_{r}\right)+\left|\alpha_{r}-\beta_{r}\right|}{2}$. By analogy with (50), for $q_{k} \geq 1$ and for $\delta=1-\zeta_{p}-\theta$ we get

$$
\frac{q_{k}^{i_{\zeta_{p}}+1}-q_{k}^{-\left(i_{\zeta_{p}}+1\right)}}{q_{k}^{N_{1}}-q_{k}^{-N_{1}}} \leq \frac{1}{q_{k}^{N_{1} \delta}}
$$

since the inequalities $\zeta_{p}+h_{1} \leq 1-\delta$ and $i_{\zeta_{p}}+1 \leq h_{1}^{-1}(1-\delta)$ hold. Hence, the analog of (47) holds, then (51)-(53) hold, too. Thereby, in view of Theorem 4, the proof is finished. Corollary 1 is proved

\section{NLBVP with integral condition}

Here we apply the results of the previous sections to NLBVP with weighted integral condition (WIC). We consider the differential problem in the rectangular $\Pi$

$$
\begin{aligned}
& \left\{\begin{array}{l}
\Delta u(x, y)=f(x, y),(x, y) \in \Pi, \\
u(x, 0)=u(x, \pi)=0,0 \leq x<1, u(0, y)=0, \mathcal{I}[u](y)=0,0 \leq y \leq \pi
\end{array}\right. \\
& \mathcal{I}[u](y) \equiv u(1, y)-\int_{\tau_{0}}^{\tau_{1}} \rho(x) u(x, y) d x,
\end{aligned}
$$

where $\rho(x) \in C\left[\tau_{0}, \tau_{1}\right],\left[\tau_{0}, \tau_{1}\right] \subset(0,1), \tau_{0}<\tau_{1}$ and $\rho(x) \not \equiv 0$ in $\left[\tau_{0}, \tau_{1}\right]$.

Theorem 5. Let the function $\rho(x)$ changes the $\operatorname{sign}^{3}$ no more than once in the interval $\left(\tau_{0}, \tau_{1}\right)$. Let :

$$
\begin{gathered}
-\infty<\int_{\tau_{0}}^{\tau_{1}} \rho(x) d x \leq 1, \text { if } \rho(x) \text { does not change the sign, or changes it from plus to minus ; } \\
\qquad \int_{\tau_{0}}^{\tau_{1}} \frac{\rho(x)+|\rho(x)|}{2} d x \leq 1 \text {, if } \rho(x) \text { changes the sign from minus to plus . }
\end{gathered}
$$

Then classical solution of (57) exists, it is an unique and a priori estimate (6) holds.

Proof. Assume that classical solution exits. Since

$$
\int_{0}^{\pi} u(1, y) \sin (k y) d y=\int_{0}^{\pi} \int_{\tau_{0}}^{\tau_{1}} \rho(x) u(x, y) d x \sin (k y) d y=\int_{\tau_{0}}^{\tau_{1}} \rho(x)\left(\int_{0}^{\pi} u(x, y) \sin (k y) d y\right) d x,
$$

then from (57)-(58), in view of (3) and by virtue of Theorem 1, we conclude that the function $X_{k}(x)$ satisfies the problem

$$
X_{k}^{\prime \prime}(x)-k^{2} X_{k}(x)=0,0<x<1, \quad X_{k}(0)=0, \quad \mathcal{I}\left[X_{k}\right]=0,
$$

where $\mathcal{I}\left[X_{k}\right]=X_{k}(1)-\int_{\tau_{0}}^{\tau_{1}} \rho(x) X_{k}(x) d x$. By virtue of the integral type of mean value theorem, we reduce WIC problem (59) to the 3-point problem

$$
X_{k}^{\prime \prime}(x)-k^{2} X_{k}(x)=0,0<x<1, \quad X_{k}(0)=0, \quad \ell\left[X_{k}\right]=0,
$$

where

$$
\ell\left[X_{k}\right]=X_{k}(1)-\left(\int_{\tau_{0}}^{\tau_{1}} \frac{\rho(x)+|\rho(x)|}{2} d x\right) X_{k}\left(\zeta_{k}\right)+\left(\int_{\tau_{0}}^{\tau_{1}} \frac{|\rho(x)|-\rho(x)}{2} d x\right) X_{k}\left(\eta_{k}\right)
$$

\footnotetext{
${ }^{3}$ The sign changing number and order are regarded as argument $x$ shifs towards $\tau_{1}$.
} 
for some $\zeta_{k} \in\left(\tau_{0}, \tau_{1}\right)$ and $\eta_{k} \in\left(\tau_{0}, \tau_{1}\right)$. Denote

$$
\alpha=\int_{\tau_{0}}^{\tau_{1}} \frac{\rho(x)+|\rho(x)|}{2} d x \quad, \quad \beta=\int_{\tau_{0}}^{\tau_{1}} \frac{|\rho(x)|-\rho(x)}{2} d x .
$$

If $\rho(x)$ does not change the sign, then:

$$
\begin{gathered}
\ell\left[X_{k}\right]=X_{k}(1)-\alpha X_{k}\left(\zeta_{k}\right) \text { and } 0 \leq \alpha \leq 1 \text {, if } \rho(x) \text { is a nonnegative function }, \\
\ell\left[X_{k}\right]=X_{k}(1)+\beta X_{k}\left(\eta_{k}\right) \text { and }-\infty<-\beta \leq 0 \text {, if } \rho(x) \text { is a nonpositive function . }
\end{gathered}
$$

If $\rho(x)$ changes the sign, then $\ell\left[X_{k}\right]=X(1)-\alpha X_{k}\left(\zeta_{k}\right)+\beta X_{k}\left(\eta_{k}\right)$, so that

$$
\begin{gathered}
-\infty<\alpha-\beta \leq 1, \quad \zeta_{k}<\eta_{k} \text { if } \rho(x) \text { changes the sign from plus to minus }, \\
\alpha \leq 1, \quad \eta_{k}<\zeta_{k} \text { if } \rho(x) \text { changes the sign from minus to plus } .
\end{gathered}
$$

Hence, in view of (61)-(62), for the 3-point NLBVP (60) the term $\boldsymbol{A}$ holds in extended form [16, p. 917], i.e., includes the option when $\alpha=0$ or $\beta=0$. Then, in view of Theorem 1, the problem (60) (and in turn the problem (59) of course) has only trivial solution $X_{k}(x) \equiv 0$, and, therefore, $u(x, y) \equiv 0$ in the rectangle $\Pi$. Since the uniqueness for the problem (57) is proved, then the existence follows from the Fredholm's property inherent such NLBVP with WIC [15, p. 68-70].

To prove a priori estimate (6) we follow Theorem 2 and, in view of (8), get WIC problem

$$
X_{k}^{\prime \prime}(x)-k^{2} X_{k}(x)=f_{k}(x), 0<x<1, \quad X_{k}(0)=0, \quad \mathcal{I}\left[X_{k}\right]=0
$$

(this problem was studied in [17]) and, in view of (60), reduce it to the multipoint problem

$$
X_{k}^{\prime \prime}(x)-k^{2} X_{k}(x)=f_{k}(x), 0<x<1, \quad X_{k}(0)=0, \quad \ell\left[X_{k}\right]=0 .
$$

In view of (61)-(62) and by virtue of Theorem 2, we ascertain that (11) holds for solution of (64) and, thereby, it holds for solution of (63). Further proof is similarly of Theorem 2. Theorem 5 is proved.

Corollary 2. Let the function $\rho(x)$ has an arbitrary order and a finite number of sign changings. If $\int_{\tau_{0}}^{\tau_{1}} \frac{\rho(x)+|\rho(x)|}{2} d x \leq 1$, then classical solution of (57) exists, it is an unique and a priori estimate (6) holds.

Proof. The proof results from Theorem 1 and Theorem 2 by using Theorem 5 . Corollary 2 is proved. Corollary 3. Let starting from plus to minus the function $\rho(x)$ changes the sign $2 n-1$ times in the interval $\left(\tau_{0}, \tau_{1}\right)$ for specified natural number $n$ and $\xi_{1}, \ldots, \xi_{2 n-1}$ are the sign changing points. Put $\xi_{0}=\tau_{0}$ and $\xi_{2 n}=\tau_{1}$. If

$$
\sum_{k=1}^{n} \frac{1}{2}\left(\int_{\xi_{2(k-1)}}^{\xi_{2 k}} \rho(x) d x+\left|\int_{\xi_{2(k-1)}}^{\xi_{2 k}} \rho(x) d x\right|\right) \leq 1,
$$

then classical solution of (57) exists, it is an unique and a priori estimate (6) holds

Proof. It results from Theorem 1-2 and by using of Theorem 3, Theorem 5. Corollary 3 is proved. 


\section{Difference application for WIC}

We consider the difference problem

$$
\left\{\begin{array}{l}
\Lambda Y=Y_{\bar{x} x}+Y_{\bar{y} y}=f\left(x_{i}, y_{j}\right), \quad\left(x_{i}, y_{j}\right) \in \Pi, \\
\left.Y\right|_{y=0}=\left.Y\right|_{y=\pi}=0, x_{i} \in[0,1),\left.\quad Y\right|_{x=0}=0, \quad y_{j} \in[0, \pi], \\
\mathcal{T} Y=\sum_{i=1}^{N_{1}} 2^{-1}\left(\rho_{i} Y_{i, j}+\rho_{i-1} Y_{i-1, j}\right) h_{1}-Y_{N_{1}, j}=0, j=\overline{1, N_{2}-1},
\end{array}\right.
$$

where $\rho(x)$ does not change the sign, $\rho(x) \in C[0,1]$ and $\rho(x) \equiv 0$ in $\left[0, \tau_{0}\right] \cup\left[\tau_{1}, 1\right], \rho_{i}=\rho\left(x_{i}\right)$, $h_{1}<\frac{1}{2} \min \left\{\tau_{0}, 1-\tau_{1}\right\}, h_{1} \leq c_{0} h_{2}, h_{1}=1 / N_{1}, h_{2}=\pi / N_{2}$.

Corollary 4. Let $u \in C^{(4)}(\bar{\Pi})$ is solution of WIC NLBVP (57). If $-\infty<\int_{\tau_{0}}^{\tau_{1}} \rho(x) d x<1$, then the solution of (65) approximates $u(x, y)$ by the second order of accuracy in terms of $h=\sqrt{h_{1}^{2}+h_{2}^{2}}$ when $h_{2} \rightarrow 0$ in respect of difference metrics $C, W_{2}^{2}$.

Proof. Following Theorem 4, for $z=Y-u$ we obtain the difference problem

$$
\Lambda z=f-\Lambda u=F,\left(i h_{1}, j h_{2}\right) \in \Pi,\left.\quad z\right|_{x=0}=\left.z\right|_{y=0}=\left.z\right|_{y=\pi}=0, \mathcal{T} z=-\mathcal{T} u,
$$

thereto $F=O\left(h^{2}\right)$ and $\mathcal{T} u=O\left(h^{2}\right)$ as a neglect of the trapezoid method. Put $z=\tilde{z}+\hat{z}$, where $\tilde{z}$ is the solution of

$$
\Lambda \tilde{z}=0,\left(i h_{1}, j h_{2}\right) \in \Pi,\left.\quad \tilde{z}\right|_{x=0}=\left.\tilde{z}\right|_{y=0}=\left.\tilde{z}\right|_{y=\pi}=0, \quad \mathcal{T} \tilde{z}=-\mathcal{T} u
$$

and $\hat{z}$ is the solution of

$$
\Lambda \hat{z}=F,\left(i h_{1}, j h_{2}\right) \in \Pi,\left.\quad \hat{z}\right|_{x=0}=\left.\hat{z}\right|_{y=0}=\left.\hat{z}\right|_{y=\pi}=0, \quad \mathcal{T} \hat{z}=0
$$

By virtue of the orthogonal system [14, p. 113] of the mesh functions $\{\sin (k y)\}_{k=1}^{k=N_{2}-1}$

$$
\tilde{z}=\sum_{k=1}^{N_{2}-1} \tilde{z}_{k} \sin (k y), \quad y=j h_{2}, \overline{j=0, N_{2}}
$$

thereto $\tilde{z}_{k}, k=\overline{1, N_{2}-1}$ is solution of the problem

$$
\Lambda_{1} \tilde{z}_{k}-\lambda_{k} \tilde{z}_{k}=0,\left.\quad \tilde{z}_{k}\right|_{x=0}=0, \quad \mathcal{T} \tilde{z}_{k}=-Q_{k}
$$

for $\Lambda_{1} \tilde{z}=\tilde{z}_{\bar{x} x}, \lambda_{k}=4 h_{2}^{-2} \sin ^{2}\left(k h_{2}\right), Q_{k}=(\mathcal{T} u)_{k}$ and, in view of [3, p. 142-143],

$$
\tilde{z}_{k_{i}}=A_{k} \sinh \left(i \ln q_{k}\right), A_{k}=-Q_{k} / \mathcal{T}\left[\sinh \left(i \ln q_{k}\right)\right], \quad i=\overline{0, N_{1}}, q_{k}=1+\lambda_{k} h_{1}^{2} / 2+\sqrt{\lambda_{k} h_{1}^{2}+\lambda_{k}^{2} h_{1}^{4} / 4}
$$

Acting by $\mathcal{T}$ we get the inequality for the denominator of the fraction $A_{k}$ :

$$
-\mathcal{T}\left[\sinh \left(i \ln q_{k}\right)\right] \geq \sinh \left(N_{1} \ln q_{k}\right)-\sum_{i=1}^{N_{1}} 2^{-1}\left(\rho_{i} \sinh \left(i \ln q_{k}\right)+\rho_{i-1} \sinh \left([i-1] \ln q_{k}\right)\right) h_{1} .
$$

If $\rho(x) \leq 0$, then $-\mathcal{T}\left[\sinh \left(i \ln q_{k}\right)\right] \geq \sinh \left(N_{1} \ln q_{k}\right)$. If $\rho(x) \geq 0$, then for $i_{\tau_{0}} h_{1} \leq \tau_{0}<\left(i_{\tau_{0}}+1\right) h_{1}$ and $i_{\tau_{1}} h_{1} \leq \tau_{1}<\left(i_{\tau_{1}}+1\right) h_{1}$

$$
-\mathcal{T}\left[\sinh \left(i \ln q_{k}\right)\right] \geq \sinh \left(N_{1} \ln q_{k}\right)-\sinh \left(\left(i_{\tau_{1}}+1\right) \ln q_{k}\right) \sum_{i=i_{\tau_{0}}+1}^{i_{\tau_{1}}+1} 2^{-1}\left(\rho_{i}+\rho_{i-1}\right) h_{1} .
$$


Denote $S_{h_{1}}=\sum_{i=i_{\tau_{0}}+1}^{i_{\tau_{1}}+1} 2^{-1}\left(\rho_{i}+\rho_{i-1}\right) h_{1}$, then

$$
-\mathcal{T}\left[\sinh \left(i \ln q_{k}\right)\right] \geq\left(1-S_{h_{1}}\right) \sinh \left(N_{1} \ln q_{k}\right)
$$

Since $\int_{0}^{1} \rho(x) d x<\lambda$ for specified $\lambda, 0<\lambda<1$, then $S_{h_{1}}<\lambda$ for sufficiently small $h_{1}$. Hence,

$$
-\mathcal{T}\left[\sinh \left(i \ln q_{k}\right)\right] \geq(1-\lambda) \sinh \left(N_{1} \ln q_{k}\right)>0
$$

In summary,

$$
-\mathcal{T}\left[\sinh \left(i \ln q_{k}\right)\right] \geq C \sinh \left(N_{1} \ln q_{k}\right)
$$

for

$$
C=\left\{\begin{array}{l}
1>0, \quad \text { if } \quad \rho(x) \leq 0, \\
1-\lambda>0, \quad \text { if } \rho(x) \geq 0 .
\end{array}\right.
$$

In view of (71) and by virtue of Theorem 4 , the proof is finished. Corollary 4 is proved.

\section{Conclusion}

We considered NLBVP for the Poisson's operator on a rectangular domain and obtained new accurate conditions of the existence, uniqueness and a priori estimate of classical solution. We applied our results and researched NLBVPs with weighted integral condition. We offered the difference variants and proved the second order of accuracy on a uniform grid.

The author thanks to Prof. Dr. A. Ashyralyev for his attention to author's preliminary results [19] which preacted this paper research.

\section{References}

1 Бицадзе А.В. О некоторых простейших обобщениях линейных эллиптических краевых задач / А.В. Бицадзе, А.А. Самарский // Докл. АН СССР. - 1969. - № 185(4). - С. 739, 740.

2 Скубачевский А.Л. О спектре некоторых нелокальных эллиптических краевых задач / А.Л. Скубачевский // Матем. сб. - 1982. - № 117(159). - 4. - С. 548-558.

3 Ильин В.А. Двумерная нелокальная краевая задача для оператора Пуассона в дифференциальной и разностной трактовках / В.А. Ильин, Е.И. Моисеев // Матем. моделирование. - 1990. - № 2(8). - C. 139-156.

4 Волков Е.А. Приближенное решение методом сеток нелокальной краевой задачи для уравнения Лапласа на прямоугольнике / Е.А. Волков // Журн. вычисл. матем. и матем. физ. - 2013. - № 53(8). - C. 1302-1313.

5 Волков Е.А. Исследование разрешимости нелокальной краевой задачи методом сжатых отображений / Е.А. Волков // Журн. вычисл. матем. и матем. физ. - 2013. - № 53(10). C. $1679-1683$.

6 Ashyralyev A. A note on the Bitsadze-Samarskii type nonlocal boundary value problem in a Banach space / A. Ashyralyev // J. Math. Anal. Appl. - 2008. - 344(1). - 557-573.

7 Ozturk E. On the Bitsadze-Samarskii type nonlocal boundary value problem with the integral condition for an elliptic equation [Electronic resource] / E. Ozturk // Conference Proceedings of Science and Technology. - 2019. - 2(1). - 76-89. ISSN: 2651-544X. - Access mode: http: // dergipark.gov.tr/cpost.

8 Volkov A. On the solution of a nonlocal problem / A. Volkov, A.A. Dosiyev, S.C. Buranay // Computers and Mathematics with Applications. - 2013. - 66(3). - 330-338. 
9 Volkov E.A. On the numerical solution of a multilevel nonlocal problem [Electronic resource] / E.A. Volkov, A.A. Dosiyev // Mediterr. J. Math. - 2016. - 13(5). - 3589-3604. - Access mode: https://doi.org/10.1007/s00009-016-0704-x .

10 Dosiyev A.A. Difference method of fourth order accuracy for the Laplace equation with multilevel nonlocal conditions [Electronic resource] / A.A. Dosiyev // Journal of Computational and Applied Mathematics. - 2019. - 354. - 587-596. - Access mode: https://doi.org/10.1016/j.cam.2018. 04.046 .

11 Dosiyev A. A fourth-order accurate difference Dirichlet problem for the approximate solution of Laplace's equation with integral boundary condition [Electronic resource] / A. Dosiyev, R. Reis // Adv. Differ. Equ. - 340. - 2019. - Access mode: https://doi.org/10.1186/s13662-019-2282-2.

12 Ильин В.А. Нелокальная краевая задача первого рода для оператора Штурма-Лиувилля в дифференциальной и разностной трактовках / В.А. Ильин, Е.И. Моисеев // Дифференциальные уравнения. - 1987. - № 23(7). - С. 1198-1207.

13 Ильин В.А. Нелокальная краевая задача второго рода для оператора Штурма-Лиувилля / В.А. Ильин, Е.И. Моисеев // Дифференциальные уравнения. - 1987. - № 23(8). - С. 1422 1431.

14 Самарский А.А. Теория разностных схем / А.А. Самарский. - М.: Наука, 1977.

15 Скубачевский А.Л. Неклассические краевые задачи / А.Л. Скубачевский // I СМФН. 2007. - № 26. - C. 3-132.

16 Dovletov D.M. On the nonlocal boundary value problem of the first kind in differential and difference interpretation / D.M. Dovletov // Differential Equations. - 1989. - 25(8). - 917-924.

17 Dovletov D.M. On some nonlocal boundary value problem in differential and difference interpretation: the dissertation ... of the candidate for physical and mathematical sciences / D.M. Dovletov. - 1989. - 128 p. Moscow, V.A. Steklov Mathematical Institute, (Russian Electronic Library, www.rsl.ru).

18 Dovletov D.M. Nonlocal boundary value problem in terms of flow for Sturm-Liouville operator in differential and difference statements / D.M. Dovletov // e-Journal of Analysis and Applied Mathematics. - 2018. - 2018(1). - 37-55.

19 Dovletov D.M. Differential and difference variants of 2-d nonlocal boundary value problem with Poissons operator / D.M. Dovletov // AIP Conference Proceedings, 2183. - 2019. - P. 0700211-070021-4. DOI:10. 1063 / 1.5136183.

20 Dovletov D.M. On a multipoint nonlocal initial value problem for a singularly-perturbed firstorder ODE / D.M. Dovletov // e-Journal of Analysis and Applied Mathematics. - 2019(2). 84-103.

Д.М. Довлетов

\title{
Тікбұрышта Пуассон операторымен берілген бейлокальді шеттік есебі және оның айырымдық интерпретациясы
}

\begin{abstract}
Жұмыста ашық тікбұрышты облыста Пуассон теңдеуі үшін бейлокальді шеттік есебінің дифференциалдық және айырымдық нұсқалары қарастырылған. Классикалық шешімінің бар болуы, жалғыздығы және априорлық бағамы анықталған. Екінші ретті дәлдікпен айырымдық схемасы көрсетілген. Салмақты интегралдық шарттары бар қосымшалар дифференциалдық және айырымдық нұсқада ұсынылған.
\end{abstract}

Kiлm сөздер: пуассон операторы, бейлокальді шеттік есебі, тікбұрыш, айырымдық схемасы. 
Д.М. Довлетов

\title{
Нелокальная краевая задача с оператором Пуассона на прямоугольнике и ее разностная интерпретация
}

\begin{abstract}
В статье изучены дифференциальные и разностные варианты нелокальной краевой задачи для уравнения Пуассона в открытой прямоугольной области. Установлены существование, единственность и априорная оценка классического решения. Представлена разностная схема второго порядка точности. Приложения с весовым интегральным условием даны в дифференциальном и разностном вариантах.
\end{abstract}

Ключевые слова: оператор Пуассона, нелокальная краевая задача, прямоугольник, разностная схема.

\section{References}

1 Bitsadze, A.V. \& Samarskii, A.A. (1969). O nekotorykh prosteishikh obobshcheniiakh lineinykh ellipticheskikh kraevykh zadach [On some simple generalizations of linear elliptic boundary problems]. Dokl. AN SSSR - USSR Academy of Science Reports, 185 (4), 739-740 [in Russian].

2 Skubachevskii, A.L. (1982). O spektre nekotorykh nelokalnykh ellipticheskikh kraevykh zadach [On the spectrum of some nonlocal elliptic boundary value problems]. Matematicheskii sbornik - Math. USSR-Sb., 117(159), 4, 548-558 [in Russian].

3 Il'in, V.A. \& Moiseev, E.I. (1990). Dvumernaia nelokalnaia kraevaia zadacha dlia operatora Puassona $\mathrm{v}$ differentsialnoi i raznostnoi traktovkakh [2-d nonlocal boundary-value problem for Poisson's operator in differential and difference variants]. Matematicheskoe modelirovanie Mathematical Modelling, 2(8), 130-156 [in Russian].

4 Volkov, E.A. (2013). Priblizhennoe reshenie metodom setok nelokalnoi kraevoi zadachi dlia uravneniia Laplasa na priamouholnike [Approximate grid solution of a nonlocal boundary value problem for Laplace's equation on a rectangle. Zhurnal vychislitelnoi matematiki i matematicheskoi fiziki - Zh. Vychisl. Mat. Mat. Fiz., 53(8), 1302-1313 [in Russian].

5 Volkov, E.A. (2013). Issledovanie razreshimosti nelokalnoi kraevoi zadachi metodom szhatykh otobrazhenii [Solvability analysis of a nonlocal boundary value problem by applying the contraction mapping principle]. Zhurnal vychislitelnoi matematiki i matematicheskoi fiziki - Zh. Vychisl. Mat. Mat. Fiz., 53(10), 1679-1683 [in Russian].

6 Ashyralyev, A (2008). A note on the Bitsadze-Samarskii type nonlocal boundary value problem in a Banach space. J. Math. Anal. Appl., 344(1), 557-573.

7 Ozturk, E (2019). On the Bitsadze-Samarskii Type Nonlocal Boundary Value Problem with the Integral Condition for an Elliptic Equation. Conference Proceedings of Science and Technology, 2(1), 76-89. ISSN: 2651-544X http://dergipark.gov.tr/cpost .

8 Volkov, A, Dosiyev, A. A. \& Buranay, S. C. (2013). On the solution of a nonlocal problem. Computers and Mathematics with Applications, 66(3), 330-338.

9 Volkov, E. A. \& Dosiyev, A. A. (2016). On the Numerical Solution of a Multilevel Nonlocal Problem. Mediterr. J. Math., 13(5), 3589-3604. https://doi.org/10.1007/s00009-016-0704-x .

10 Dosiyev, A. A. (2019). Difference method of fourth order accuracy for the Laplace equation with multilevel nonlocal conditions. Journal of Computational and Applied Mathematics, 354, 587-596. https://doi.org/10.1016/j.cam.2018.04.046 .

11 Dosiyev, A. \& Reis, R. (2019). A fourth-order accurate difference Dirichlet problem for the approximate solution of Laplace's equation with integral boundary condition. Adv. Differ. Equ., 340. https://doi.org/10. 1186/s13662-019-2282-2 . 
12 Il'in, V.A. \& Moiseev, E.I. (1987). Nelokalnaia kraevaia zadacha pervoho roda dlia operatora Shturma-Liuvillia v differentsialnoi i raznostnoi traktovkakh [First kind nonlocal boundary value problem for Sturm-Liouville operator in differential and difference treatment]. Differentsialnye uravneniia - Differential Equations, 23(7), 1198-1207 [in Russian].

13 Il'in, V.A. \& Moiseev, E.I. (1987). Nelokalnaia kraevaia zadacha vtoroho roda dlia operatora Shturma-Liuvillia [Second kind nonlocal boundary value problem for Sturm-Liouville operator in differential and difference treatment. Differentsialnye uravneniia - Differential Equations, 23(8), 1422-1431 [in Russian].

14 Samarskii, A.A. (1977) Teoriia raznostnykh skhem [The Theory of Difference Schemes]. Moscow: Nauka [in Russian].

15 Skubachevskii, A.L. (2008). Neklassicheskie kraevye zadachi [Nonclassical boundary value problems, I]. I SMFN - Journal of Mathematical Sciences, 155(2), 199-334 [in Russian].

16 Dovletov, D. M. (1989). On the nonlocal boundary value problem of the first kind in differential and difference interpretation. Differential Equations, 25(8), 917-924.

17 Dovletov, D.M. (1989). On some nonlocal boundary value problem in differential and difference interpretation. The dissertation ... of the candidate for physical and mathematical sciences. Moscow, V.A. Steklov Mathematical Institute, (Russian Electronic Library, www.rsl.ru).

18 Dovletov, D. M. (2018). Nonlocal boundary value problem in terms of flow for Sturm-Liouville operator in differential and difference statements, e-Journal of Analysis and Applied Mathematics, 2018(1), 37-55.

19 Dovletov, D.M. (2019). Differential and difference variants of 2-d nonlocal boundary value problem with Poissons operator. AIP Conference Proceedings, 2183 -P. 070021-1-070021-4 DOI:10.1063 / 1.5136183 .

20 Dovletov D.M. (2019). On a multipoint nonlocal initial value problem for a singularly-perturbed first-order ODE. e-Journal of Analysis and Applied Mathematics, 2019(2), 84-103. 